\title{
Promoting Azerbaijani Students' Intercultural Competence through Distance Education of Foreign Languages
}

\author{
Sevda Imanova \\ Department of Science \\ Azerbaijan University of Languages \\ Baku, Azerbaijan \\ Email: sevda.imanova11@gmail.com
}

Received: $7 / 22 / 2021$

Accepted: 8/8/ 2021

Published: 9/24/2021

\begin{abstract}
The main aim of this study is to determine the advantages and disadvantages of distance teaching and promoting Intercultural Competence in learning foreign languages in the Azerbaijani higher education system. Nowadays the growing tendency of remote education proves that, education has become more reachable in comparison to the past decades. At the same time, distance education has brought new demands and regulations to the education system. The COVID19outbreak has necessitated the online teaching process resulting in specific problems, including the maintenance of interaction in online teaching. Thus, this study explores both benefits and drawbacks of teaching foreign languages through distance learning in Azerbaijan. In this research, a quantitative research method in the form of a survey has been utilized to explore the tendency of teaching intercultural competence in foreign language classes at universities. Finally, it may be concluded that distance education provides enormous opportunities to practice intercultural communicative competence by using modern information technologies and does not differ much from face-to-face learning.
\end{abstract}

Keywords: Azerbaijani higher education, distance education, foreign languages, intercultural competence, a mediator of cultures, motivation, online teaching

Cite as: Imanova, S. (2021). Promoting Azerbaijani Students' Intercultural Competence through Distance Education of Foreign Languages. Arab World English Journal, 12 (3) 232241. DOI: https://dx.doi.org/10.24093/awej/vol12no3.16 


\section{Introduction}

New socio-political, economic, and cultural realities have led to the need to adopt foreign language-teaching goals in higher education. Azerbaijan has joined the world community, which necessitates new approaches in teaching a foreign language to students in higher education. The issues of forming the linguistic skills of a new type in the methodology of teaching foreign languages have become a dominant goal of the Azerbaijan University of Languages to solve. To acquire the properties of a mediator of cultures and carry out productive intercultural interaction, a person with linguistic skills must have Intercultural Competence (after this - IC).

Due to the COVID-19 pandemic, distance education became the main form of teaching and learning. Unfortunately, the problems of distance education are in both theoretical and practical spheres. Academic issues cover the design and appliance of new educational technologies. Distance learning is a form of the education process, based on operative, regular dialogue, feedback between a teacher and learners through technical means such as telecommunications and computer networks. This form of education is widely used in many European developed countries and reflected in the Bologna education system. In recent years, the popularity of distance education has grown dramatically. In this regard, this is the most convenient and inexpensive form of education for all population levels. The purpose of distance education is to improve the skills of students using modern information technologies. The first attempt to create distance education was made in 1840 when Pitman began teaching shorthand to students in the United Kingdom by mail (Bates, 2006).

As for Azerbaijan, in tertiary education, online or distance teaching and learning formats were not widely practiced until the Covid-19 outbreak. Up to the pandemic period, teaching in a classroom environment was the only way in the education system of Azerbaijan and online teaching could not compete with it. Distance education was considered an additional tool but not compulsory. Experts believe that full-time education is good in terms of quality, and people who study full-time have always been distinguished by their professional skills. However, due to some definite reasons, distance education was the most appropriate and suitable way of learning for people who could not expand the scope of knowledge in a classroom environment. Unlike this, teachers from the old generation prefer to use traditional ways of teaching, and they have a critical attitude towards the possibilities of distance learning in general and including teaching IC in the online environment. So, the primary purpose of the study is to show more relevant teaching form of IC in Azerbaijan.

\section{The Review of Literature}

There are many definitions of IC. However, there is no single definition accepted by all researchers. Deardorff (2016) defines IC as 'the ability to develop targeted knowledge, skills and attitudes that lead to visible behavior and communication that is both effective and appropriate in intercultural interactions.' (2016, p. 243).

For Sadokhin (2007), IC is a combination of knowledge, skills, and abilities with the help of which an individual can successfully communicate with partners from others. Byram mentions IC as 'Knowledge of others; knowledge of self; skills to interpret and relate; skills to discover and interact; to value others' values, beliefs, and behaviors.' (1997, p. 34). 
To deal with the promotion of IC among Azerbaijani students, it is necessary to dwell in more details on including understanding the values and norms that are relevant in a specific situation of interaction: high level of social responsibility, building relationships and partnerships with representatives of different communities, comprehension of the accumulated experience in its various aspects. Some researchers pay attention to cultural awareness, knowledge, and motivation, while others focus on communication and behavioral skills. In their studies, Byram (1997) and Starkey discussed the formation of critical thinking and active citizenship (Osler \& Starkey, 2015). This means the ability of critically assessing the values, norms, products of both native and other cultures based on clear criteria is significantly essential. Regarding this, the teacher provides students with opportunities for reflection, constructive criticism, and encourages them to participate in creative activities by providing meaning and direction. It is worth dwelling in more detail on Bayram's model. According to his approach, the following are the most critical components of IC among many aspects: self-awareness, as well as awareness of another culture; communication abilities, taking into account the cultural differences; the ability to master cultural knowledge; the ability to interpret documents, facts, events and any other cultural artifacts (Byram, 1997).

There is a vast number of researches devoted to the theoretical foundations and practical instructions for using technologies in teaching foreign languages. However, the problem of the formation and assessment of IC in foreign language lessons through using distance education remains theoretically and practically insufficient. Now, there are quite a few studies devoted to the problem of tools for the formation of IC (Krotik, K.V. \& Morhun O.O. 2021; Nikolaeva \& Suslennikova, 2020; Robert \& Ining, 2016).

The formation of the distance education system is one of the strategic directions of modernization in higher education in post-Soviet countries. The analysis of the educational practice of the former USSR (Union of Soviet Socialist Republics) countries shows specific general trends in the development of distance education. For example, a characteristic feature of the current stage of development of distance education in Russia is the widespread use of various modern educational technologies adopted worldwide. This process began in the first half of the 1990s.

In Azerbaijan, the establishment of distance education was realized through the approval of the new Education Law on June 19, 2009. According to Article 13 of the mentioned Law, there are four forms of education in Azerbaijan, namely full-time, part-time, distance and free (external). Over time, the Ministry of Education has developed certain documents of conceptual and strategic importance for applying distance technologies in some areas (The Law on Education, 2009).

Referring to Krotik and Morhun (2021) the 'Distance learning is a form of education using computer and telecommunication technologies that provide interactive interaction between teachers and pupils/students at different training and self-guided work with information network materials.' (2021, p. 254)

As noted by Hargis (2020), we also hope 'that the lesson learned from the pandemic is not one of holding our breath, treading water and waiting for the routine of 'school' to return. 
Instead, we should take this opportunity to completely rethink education, especially to be more inclusive and accessible to all of our students. To accomplish this, we will need to maintain our insightful academic lens in reviewing the vast literature on effective online teaching and learning, then select the ones that align with specific institutional missions.'(2020, p.4)

\section{Methods \& Participants}

In this research, 33 lecturers teaching English in the language department of Azerbaijan University of Languages participated. Non-probability sampling methods were adopted to choose the sample of this study. Besides including the demographic question, questionnaire items concerning teaching online were listed in the online survey. The questionnaire items were prepared based on the available materials and literature. The link for the beforementioned survey is following: https://docs.google.com/forms/d/15IUAlfh3Kx8_eeiWoBaCC5YBTRXndlSnKCbTACDg7OY/e dit?usp=sharing\&urp=gmail_link.

\section{Results}

Thirty-three lecturers teaching foreign languages in different departments at Azerbaijan University of Languages participated in this study. All the respondents who attended the survey are female.

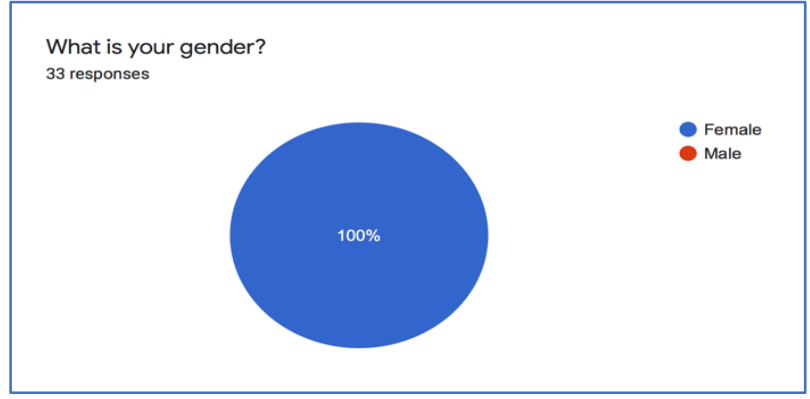

Figure 1. Gender of the respondents

According to the results, a little less than $40 \%$ of the participants responded that they have 611 years of teaching experience, and each third has been teaching more than 20 years at the university.

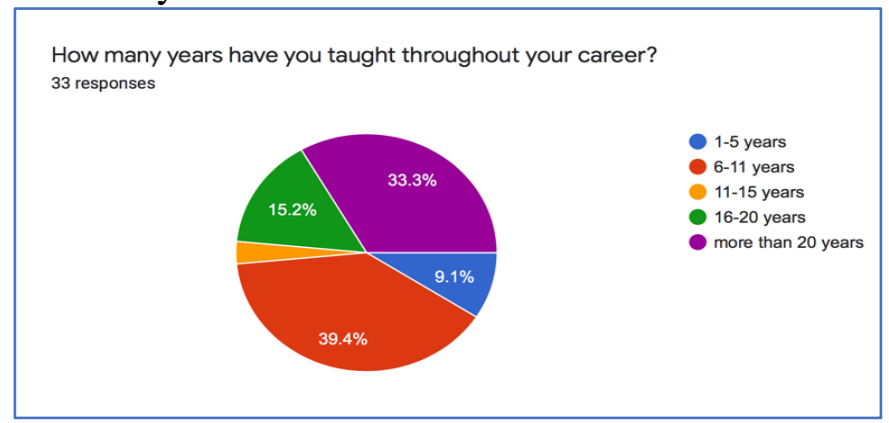

Figure 2. Teaching experience

The participants were asked about their experience in teaching online. Based on the responses, $46.9 \%$ of them noted that they are very good at leading online, and $43.8 \%$ of the 
lecturers consider that their skills in teaching online are good. At the same time, the proportion of respondents who answered that their online teaching experience is excellent is only $9.4 \%$.

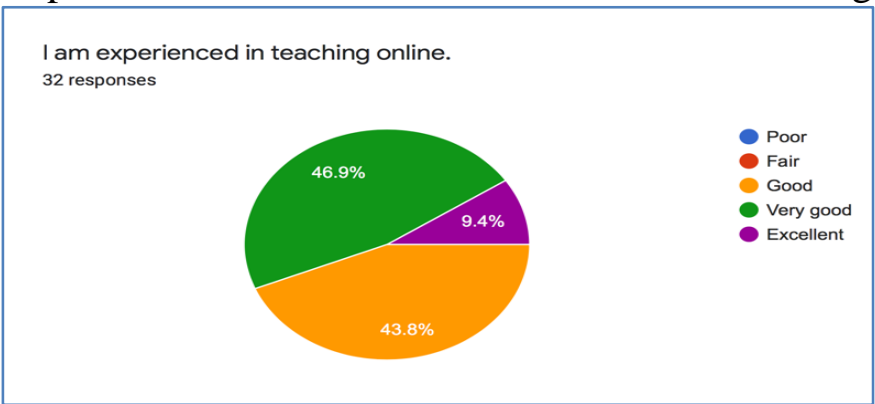

Figure 3. Online teaching experience

The questionnaire has included the question of the importance of face-to-face communication while teaching. Fifty-four point five percent of the respondents said that face-to-face communication is very vital while teaching and $27.3 \%$ of participants think that it is moderately important to teach face-to-face.

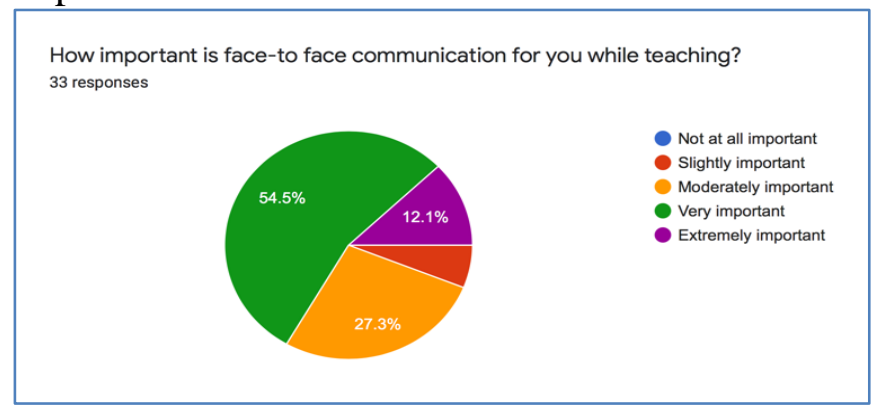

Figure 4. Importance of face-to-face communication while teaching

In language classes, $48.5 \%$ of the participants concur that culture should be integrated into language teaching, while $33.3 \%$ strongly agree with the statement shown in the questionnaire.

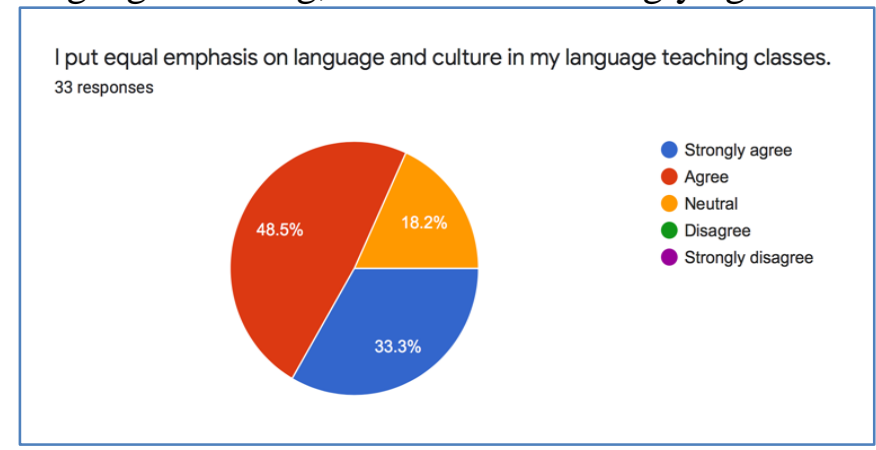

Figure 5. Language and culture

The respondents were asked if they enjoy teaching intercultural communicative competence in online language lessons. Most respondents (54.5\%) answered that teaching intercultural communicative competence in online foreign language lessons is essential. Although $36.4 \%$ of the participants think that teaching intercultural communicative competence is vital in foreign language classes, but they are willing to change few things in the program. 


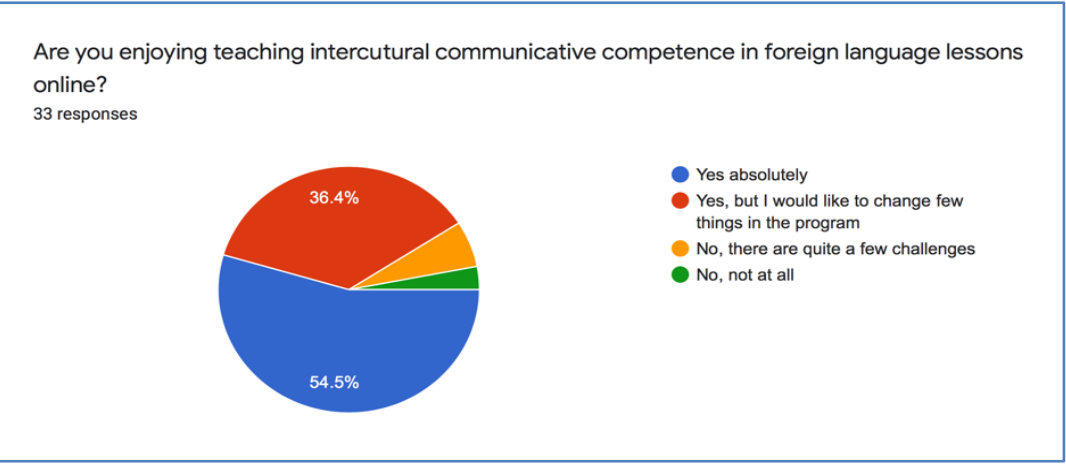

Figure 6. Teaching intercultural communicative competence in foreign lessons online

In online discussions, keeping students engaged in determining the difference between their own and other cultures is the last question item included in the questionnaire. The percentage of respondents who agree with this statement is $69.6 \%$. In comparison, 33.3\% strongly agree that it is vital to contribute to students to search for the differences between native and foreign cultures.

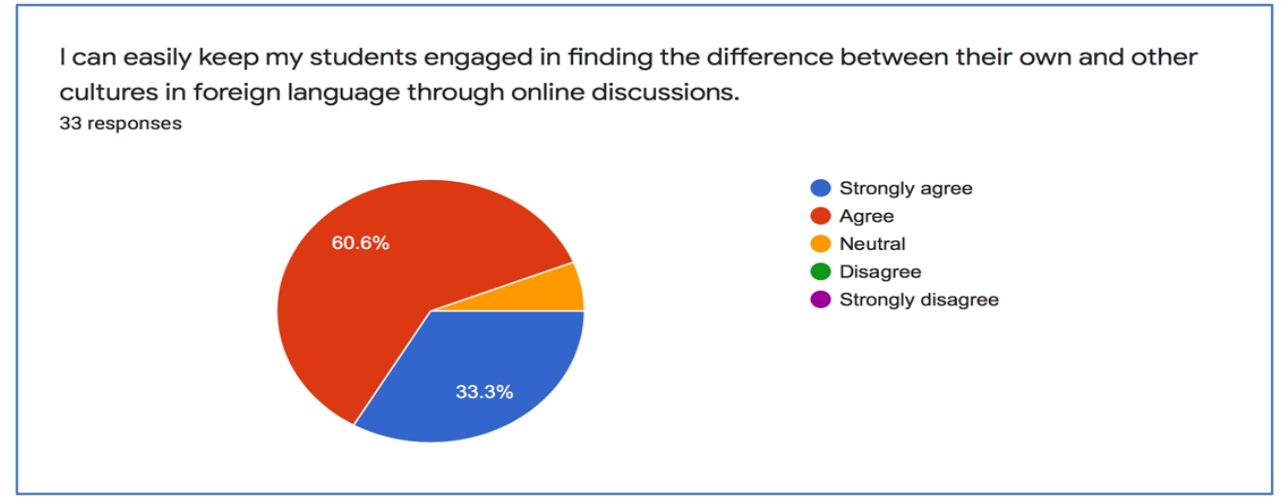

Figure 7. Difference between own and other cultures

\section{Discussion}

Distance education has many advantages over face-to-face and correspondence forms of education, such as its affordability, cheapness, flexibility, and so on. At the same time, distance education optimally develops learners' independence, activity, and creativity compared to traditional forms of education. In addition, more scientific information can be obtained quickly, and the students' conscious and logical ability to acquire systematic knowledge expands. Distance education can be as effective as traditional education if the technology and teaching method meet the goals and capabilities of the student and teacher.

In addition, distance education allows a person to overcome psychological barriers related to communication qualities, such as shyness and phobia of public speaking and is mobile. Therefore, the student always has access to current issues. Such education fosters the discipline of planning and supervising the process of self-education. Like any form of education, it is a reciprocal process, and the 'pedagogue' factor is crucial in the absence of live communication with the student.'

Despite the beforementioned, distance education also has the following disadvantages: 
- Does not allow to take into account individual differences in the level of education and professional experience of students.

- The loss of live communication between teacher and student in the distance education system.

- Training courses are not interactive enough.

Nevertheless, distance education will develop and, over time, will take its rightful place among other forms of education. It is expedient to use the most common educational activities in distance education in the world practice, which improve distance education - teleconferences, business games, group discussions, methods of working with interactive teaching materials, case study methods. It should also be taken into account that the form of teaching in the distance education system is entirely different: in this case, tutorials, practical classes, and laboratory work in the form of active and intensive courses (business games, 'brainstorming', and 'case study') are preferred. Another effective form of organization of the educational process when using distance learning is group and individual counseling. This form is given a special place in the process of solving various problems faced by students. Teachers can arrange virtual visits, trips, or collaborative, class-to-class calls, which will promote students' activity and motivation.

In its turn, motivation is one of the most important and, at the same time, the problematic factors in foreign language and culture learning. In distance learning form, low motivation is the definite must be solved problem. Motivation being a complex phenomenon in foreign language teaching, performs a function that covers three aspects:

- A motivated student has a strong desire and goal to master the language and culture and succeed;

- Motivated student strives to work on language, to do homework productively and efficiently, to look for opportunities of using additional materials to learn more;

- Motivated student enjoys learning a foreign language and culture (Kudryavtseva, 2014).

Motivation is increased when teachers and learners have a joint commitment to developing language skills and IC.

Some methodological instructions for the successful development of the distance education system in Azerbaijan:

1) To investigate the social demand, requirement, need, order: learners and teachers' attitude, actual condition of the considerably new education format for Azerbaijan and its perspectives;

2) To study developed countries' experience in the relevant field and the main approaches to the issue;

3) To study and prepare the scientific-methodological, pedagogical, and educational maintenance of the IC forming through distance education for Azerbaijan;

4) To design a national development program for distance education development;

5) To design special syllabi, program culture-based teaching material for the distance education system;

6) To provide teachers, Methodists with special training for IC forming skills and proficiency in the distance education system;

7) To design appropriate forming methods and IC assessment models;

8) To include to the teaching process in cooperation with other countries, representatives of target culture joint classes, collaborative work. 
Teaching materials for distance education must meet the following requirements: information transparency, non-forcible acceptance of teaching materials, their simplicity for comprehension, ease of editing and abstracting, economy, high level of self-control, interactive opportunities for feedback. Both the entire distance learning process and each training course should begin with introductory sessions and comments. In these classes, the student learns about the teacher, becomes acquainted with the summary, goals, objectives of the course, textbooks and additional teaching materials, as well as the form of current and final control. The development of distance pedagogy in our country should also be considered a priority issue that needs to be addressed immediately.

An analysis of practice shows that a significant part of graduates of foreign language faculties does not have IC to a degree sufficient to form students' ability to intercultural interaction with representatives of foreign languages. Traditional approaches do not fully take into account the specifics of language as culturally determined behavior. Preparation for the mediator of cultures and the implementation of productive intercultural interaction of future teachers of foreign languages is carried out in artificial conditions, and educational communication with fellow students and teachers cannot fully compensate for the lack of direct interaction with native speakers. In this situation, it seems necessary to introduce Web 2.0 technologies in the process of forming IC of teachers of foreign languages.

According to experts in education, 5-10\% of the teaching material is mastered during the lecture, $10-20 \%$ is read during the free reading of the teaching literature, and up to $50 \%$ is dominated during the group discussion of the material. In the process of the practical application of new knowledge, skill is close to 75\%, the highest level of mastery (90\%) can be achieved when teaching others (Aghayev, 2020). Distance education classes do not differ much from the curriculum taught in regular universities. The only difference of distance education is communication way between the student and the teacher.

\section{Conclusion}

Based on the results obtained from the survey, the majority of respondents consider that combining culture with a language teaching is essential in terms of better understanding foreign culture and cultural differences.

Distance education combines different educational programs, technologies, and forms of teaching. The form of teaching in the distance education system is entirely different: in this case, tutorials, practical classes, and laboratory work in the form of active and intensive courses (business games, 'brainstorming' and 'case study') are preferred. It is expedient to use the most common educational activities in distance education in the world practice - teleconferences, business games, group discussions, methods of working with interactive teaching materials, case study methods. Another effective form of organization of the educational process while using distance learning is group and individual counseling. This form is given a special place in the process of solving various problems faced by students.

Some practicing teachers note that in the process of forming students' IC, a particular role can play internet communication as it has pretty diverse formats: web forum, audio-video conference, chat, blog, e-mail, online file exchange, webinars, video clips, audio scripts, 
meetings, diagrams, online testing, interactive tutorials, etc. Video conferencing for educational purposes usually creates a situation in which students get the opportunity not only to formulate their thoughts in a foreign language but also to listen to each other's opinions and compare their points of view.

Thus, the further development of distance education means a structured environment learning that combines audio and video conferencing, text chat, interactive whiteboards, applications on digital devices, testing tools and feedback, forums, and webinars.

From this study, it seems that the use of social networks develops the students' motivation, which is a crucial factor in forming IC through both distance and blended education. In this regard, it seems promising to conduct a series of theoretical and practical studies on the effectiveness of means and methods of distance learning in the implementation of forming IC among students of Azerbaijani universities.

\section{About the Author}

Dr. Sevda Imanova is an Associate Professor of Pedagogy at Azerbaijan University of Languages (AUL) and currently she is the Head of Department of Science. Her areas of research interest include forming of students' intercultural competence and assessing its level at foreign languages classes. ORCid: https://orcid.org/0000-0003-2292-8494

\section{References}

Aghayev, S. (2020).Tadrisda distant tahsil. [Distance education] Retrieved from:

https://muallim.edu.az/news.php?id=12524

Bates, T. (2006). Who are the founding fathers of distance education? Available at: https://www.tonybates.ca/2016/09/17/who-are-the-founding-fathers-of-distance-education/

Byram, M. (1997). Teaching and Assessing Intercultural Communicative Competence. Bristol, UK: Multilingual Matters.

Deardorff, D. K. (2016). The Identification and Assessment of Intercultural Competence as a Student Outcome of Internationalization at Institutions of Higher Education in the United States. Journal of Studies in International Education, 10, 241-266.

Law on Education (2009). Baku. Retrieved from: http://e-qanun.az/framework/18343

Hargis, J. (2020). What is effective online teaching and learning in higher education? Academia Letters, Article 13. https://doi.org/10.20935/AL13

Krotik, K.V. \& Morhun O.O. (2021). The Development of Intercultural Competence of Secondary School Pupils and University Students. Arab World English Journal, 11 244-263. DOI: https://dx.doi.org/10.24093/awej/covid.19.

Kudryavtseva, M., G. (2014). Possibilities of distance learning as a means of foreign language learning motivation among students of economics. Procedia - Social and Behavioral Sciences, 152, 1214 - 1218. DOI: 10.1016/j.sbspro.2014.09.301

Retrieved from: https://cyberleninka.org/article/n/942554.pdf

Nikolaeva, M., \& Suslennikova, E. (2020). E inter-cultural competence formation for students in distance learning. Гуманитарные науки, 7(2), 85-89. Available at: http://195.2.77.169/files/fcd4da12-461e-4039-9f64-f8a1286e48ca

Osler, A., \& Starkey, H. (2015). Education for cosmopolitan citizenship: A framework for language learning. Argentinian Journal of Applied Linguistics, 3(2), 30-39. 
Arab World English Journal (AWEJ) Volume 12. Number 3. September 2021

Promoting Azerbaijani Students' Intercultural Competence through Distance

Imanova

Robert, A., \& Ining, C. (2016). Intercultural competence development for open and distance learning. Available at: http://oasis.col.org/handle/11599/2553

Sadokhyn, A.P. (2007). Межкультурная компетентность: понятие. структура, пути формирования. [Intercultural Competence: Concept, Structure, Ways of Forming] Available at: https://cyberleninka.ru/article/n/mezhkulturnaya-kompetentnost-ponyatie-struktura-putiformirovaniya 